\title{
Lymphomatoid Granulomatosis as a Debut of Common Variable Immunodeficiency: A Case Report and Review of Literature
}

\author{
Magdalena Fernández-García ${ }^{1 *}$, Tetyana Zhuravetska², Jose Luis Rodríguez ${ }^{3}$, Elsa 0ts ${ }^{2}$ \\ ${ }^{1}$ Department of Internal Medicine, Hospital Marqués de Valdecilla-IDIVAL, University of Cantabria, RETICEF, \\ Santander, Spain \\ ${ }^{2}$ Department of Intensive Care, Hospital Marqués de Valdecilla, Santander, Spain \\ ${ }^{3}$ Department of Anatomic Pathology, Hospital Marqués de Valdecilla, Santander, Spain \\ Email: "magdafergar@yahoo.es
}

Received 21 August 2014; revised 6 October 2014; accepted 21 October 2014

Copyright (C) 2014 by authors and Scientific Research Publishing Inc.

This work is licensed under the Creative Commons Attribution International License (CC BY).

http://creativecommons.org/licenses/by/4.0/

(c) (i) Open Access

\begin{abstract}
Lymphomatoid granulomatosis, currently called as extranodal angiocentric and angiodestructive immunoproliferative disorder, is a rare entity of unclear etiology. It involves most frequently lungs, central nervous system and skin. The clinical course is variable, but mortality is high. Today, it represents a diagnostic challenge because it can emulate autoimmunity, infection, and malignancy processes. Optimal therapy scheme is still unknown. We report the case of a 20 year-old man presenting with fever, weight loss, sweating, multiple bilateral lung nodules on the chest $\mathrm{X}$ ray and cutaneous involvement.
\end{abstract}

\section{Keywords}

Lymphomatoid Granulomatosis, Common Variable Immunodeficiency, Epstein-Barr Virus

\section{Introduction}

Lymphomatoid granulomatosis (LG) is a B cell proliferation of uncertain malignant potential. This entity likely represents a lymphoproliferative disorder in the family of Epstein-Barr virus (EBV)-associated B cell lymphomas although its absence does not exclude the diagnosis. Laboratory tests are often nonspecific but in most cases show increases in IgG and IgM. LG can be seen in patients with an underlying immunodeficiency, whether

\footnotetext{
"Corresponding author.
}

How to cite this paper: Fernández-García, M., Zhuravetska, T., Rodríguez, J.L. and Ots, E. (2014) Lymphomatoid Granulomatosis as a Debut of Common Variable Immunodeficiency: A Case Report and Review of Literature. Journal of Biosciences and Medicines, 2, 13-15. http://dx.doi.org/10.4236/jbm.2014.28002 
drug-induced or primary and secondary immunodeficiencies. The clinical course is variable and it is related with the histologic grade of the lesions. Common variable immunodeficiency (CVID) is the most prevalent form of severe antibody deficiency. CVID patients may remain asymptomatic, suffer repeated infections or develop autoimmune and/or neoplastic diseases like LG.

\section{Case Report}

A 20 year-old man without relevant medical history was referred from his reference hospital where he was admitted with the diagnosis of right lower extremity cellulitis. He referred an involuntary weight loss, about $10 \mathrm{~kg}$ for the last two months. Despite the resolution of the cutaneous infection, mild fever persisted with the appearance of fever peaks. On arrival at our hospital, his temperature was $39^{\circ} \mathrm{C}$, his blood pressure, heart and respiratory rates were 90/70 mmHg, 130 b.p.m and 32 b.p.m. Physical examination showed pallor, profuse sweating, bilateral crepitant rales and hepato-splenomegaly without adenopathies. Analytical results were $\mathrm{Hb} 11 \mathrm{~g} / \mathrm{dL}$, ferritin $1535 \mathrm{ng} / \mathrm{mL}, 4700$ leukocytes, $\mathrm{LDH} 413$, plasma albumin 2.6, total protein 3.7, PCR $7.5 \mathrm{mg} / \mathrm{dL}$, and ESR 8 $\mathrm{mm} / \mathrm{h}$. Arterial blood gas $\left(\mathrm{FiO}_{2} 1.0\right)$ showed $\mathrm{pH} 7.45, \mathrm{pCO}_{2} 33.8 \mathrm{mmHg}, \mathrm{pO}_{2} 47.5 \mathrm{mmHg}, \mathrm{HCO}_{3} 24.3 \mathrm{mmol} / \mathrm{L}$, and $\mathrm{BE}-0.3$. Empirical treatments (wide spectrum antibiotherapy, hemodynamic and respiratory support) were started.

CT-scan revealed multiple bilateral lung nodules (Figure 1(a)) and a striking hepato-splenomegaly. The retroperitoneal area was occupied by multiple adenopathic conglomerates. An echocardiogram was normal. Serological tests (hepatotropic virus, toxoplasma, L. pneumophila, M. pneumoniae, Bartonella, Borrelia, C. Burnetti, and galactomannan test) were negative. Blood and sputum cultures were sterile. The tuberculin skin test, ANA, ANCA, and rheumatoid factor were negative. Blood determinations of immunoglobulins were IgG 65 (NR 734 $1486 \mathrm{mg} / \mathrm{dL}$ ), IgA 25 (NR 49 - 401) and $\operatorname{IgM}<20$ (NR $40-230 \mathrm{mg} / \mathrm{dL}$ ), so a diagnosis consistent with common variable immunodeficiency (CVID) was set and replacement with intravenous immunoglobulin was initiated (IVIg).

The patient developed progressive respiratory distress without fever remission. A fibrobronchoscopy with transbronchial biopsies was done. Two subcutaneous nodules on the anterior abdominal wall, which were not present on admission, appeared and they were biopsied. The histopathological study and the immunohistochemical analysis of the conglomerate showed large groups of phenotype B lymphocytes (CD 20+) with a high proliferative index (Ki67), and a pattern of angiocentric affectation with large areas of vascular destruction consistent with Lymphomatoid Granulomatosis (LG), Grade 3 (Figure 1(b)). Studies of the skin biopsy were similar. Immunostain for Epstein-Barr virus was negative. The transbronchial biopsy showed a lymphoid infiltrate with acute vascular microthrombosis. The histopathological and microbiologic studies of bone marrow were normal. The patient was treated with CHOP-R (cyclophosphamide, adriamycin, vincristine, and prednisone) chemotherapy but developed severe neutropenia complicated by sepsis and died.

\section{Discussion}

LG is a rare entity of unclear etiology with a high mortality rate [1]. The incidence is higher among young male adults especially when states of immunosuppression coexist [2] [3]. The main differential diagnoses are granulomatous polyangiitis, lymphoreticular lung proliferations, Langerhans cell histiocytosis and primary pulmonary nodular lymphoreticular hyperplasia. Histologic grade is directly related to treatment response. Grade 3 is considered the worst prognosis.

CVID is a primary immunodeficiency characterized by an impaired differentiation of B cells with disrupted immunoglobulin production. The incidence of lymphoid tumors is higher in CVID patients compared with the general population. Most of these are well-differentiated NHL B cell extranodal diseases [4]. Nowadays, CVID is considered a heterogeneous group of disorders with a primary antibody deficiency as element of binding. In this sense, there are described five different clinical phenotypes: only infections, autoimmune phenomena, polyclonal lymphocytic infiltration, enteropathy, and lymphoid malignancies. In our case, the diagnosed CVID was the probably causative factor of LG, a very exceptional situation. In our literature review we only found one published case of an adult patient who developed a LG in context of a CVID previously diagnosed [5].

The aim of our work is to call attention on two apparently unrelated conditions with a fatal outcome in a young patient with no prior pathological history. LG should be included in the differential diagnosis of multi- 


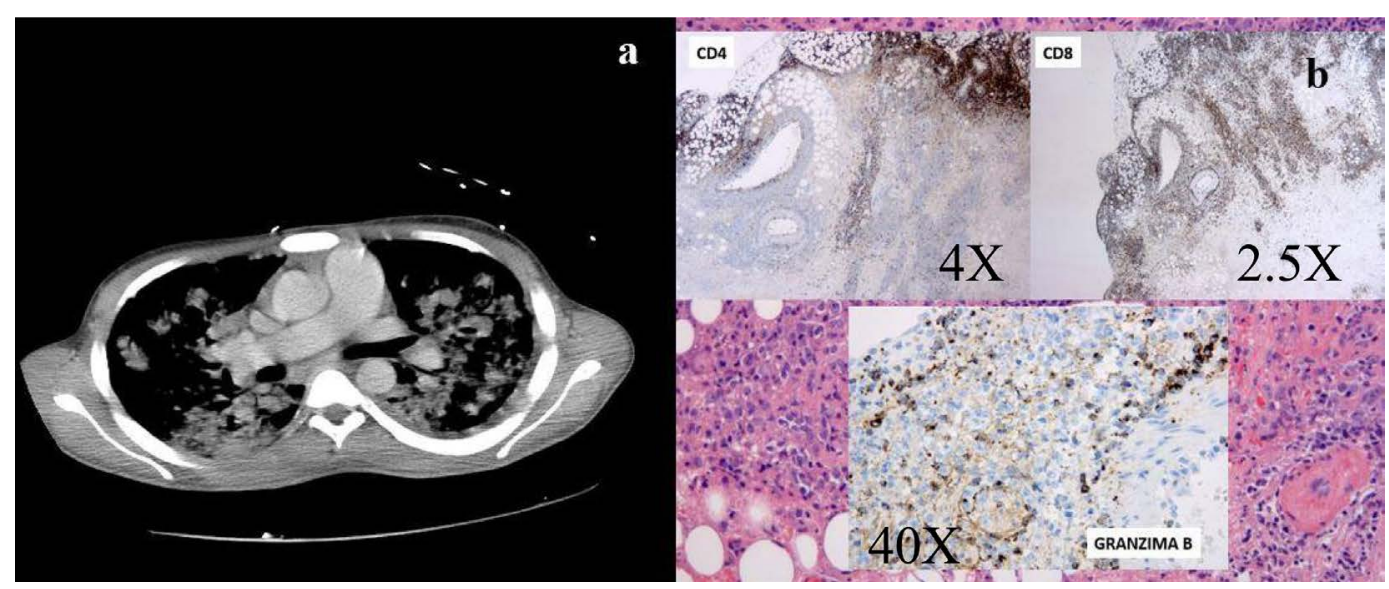

Figure 1. Panel (a) Chest-CT Scan: multiple bilateral lung nodules; Panel (b) Lymph Node Biopsy (hematoxylin and eosin stain): large phenotype B lymphomatous cells with a pattern of angiocentric affectation with large necrosis areas. In the sample predominate numerous lymphocytes CD4 phenotype in mild tumoral areas (immunohistochemistry using antibodies anti-CD4) and phenotype CD8 and granzyme B positive in frank neoplastic areas (immunohistochemistry using antibodies anti-CD8 and anti-granzyme B, respectively).

nodular pattern on chest-X ray and cutaneous lesions. The optimal therapy is still unknown, so further studies are needed to clarify its origin and to improve the prognosis. Internists, pneumologists, hematologists and dermatologists must recognize this condition in order to initiate the appropriate treatment as soon as possible.

\section{Acknowledgements}

We are gratefully indebted to Dra. Marta Cuadrado Rosón, from the Department of Anatomic Pathology, Hospital Manacor, Mallorca, for his critical revision of the manuscript.

\section{References}

[1] Swerdlow, S., Campo, E., Lee Harris, N., Jaffe, E., Pileri, S., Stein, H., et al. (2008) WHO Classification of Tumors of Haematopoietic and Lymphoid Tissues. IARC Press, Lyon.

[2] Inaba, M., Ushijim, S., Hirata, N., Saisyoji, T., Kitaoka, M. and Yoshinaga, T. (2011) Methotrexate-Related Lymphomatoid Granulomatosis in a Patient with Rheumatoid Arthritis. Nihon Kokyuki Gakkai Zasshi, 49, 597-601.

[3] Wyen, C., Stenzel, W., Hoffmann, C., Lehmann, C., Deckert, M. and Fätkenheuer, G. (2007) Fatal Cerebral Lymphomatoid Granulomatosis in an HIV-1-Infected Patient. Journal of Infection, 54, 175-178. http://dx.doi.org/10.1016/j.jinf.2006.11.003

[4] Cunningham-Rundles, C. and Bodian, C. (1999) Common Variable Immunodeficiency: Clinical and Immunological Features of 248 Patients. Clinical Immunology, 92, 34-48. http://dx.doi.org/10.1006/clim.1999.4725

[5] Váróczy, L., Gergely, L., Szakáll, S. and Illés, A. (2002) Angiocentric lymphomatoid Granulomatosis and Severe Hypogammaglobulinaemia. Haematologia, 32, 535-541. 
Scientific Research Publishing (SCIRP) is one of the largest Open Access journal publishers. It is currently publishing more than 200 open access, online, peer-reviewed journals covering a wide range of academic disciplines. SCIRP serves the worldwide academic communities and contributes to the progress and application of science with its publication.

Other selected journals from SCIRP are listed as below. Submit your manuscript to us via either submit@scirp.org or Online Submission Portal.
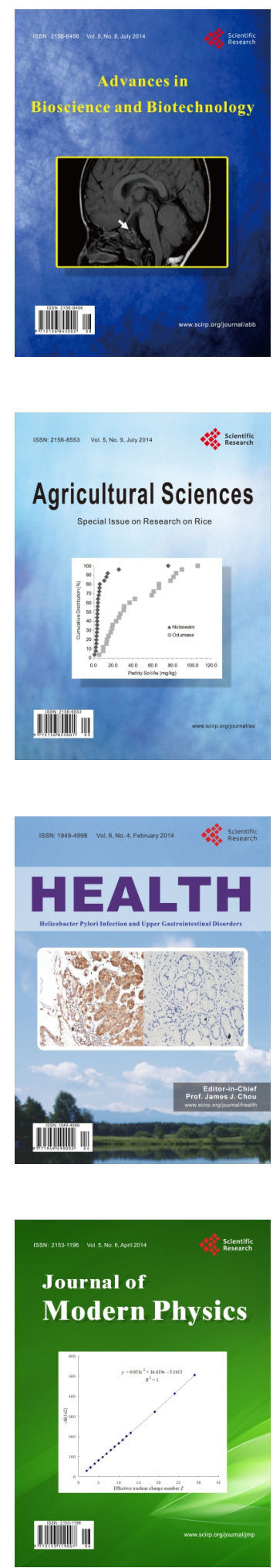
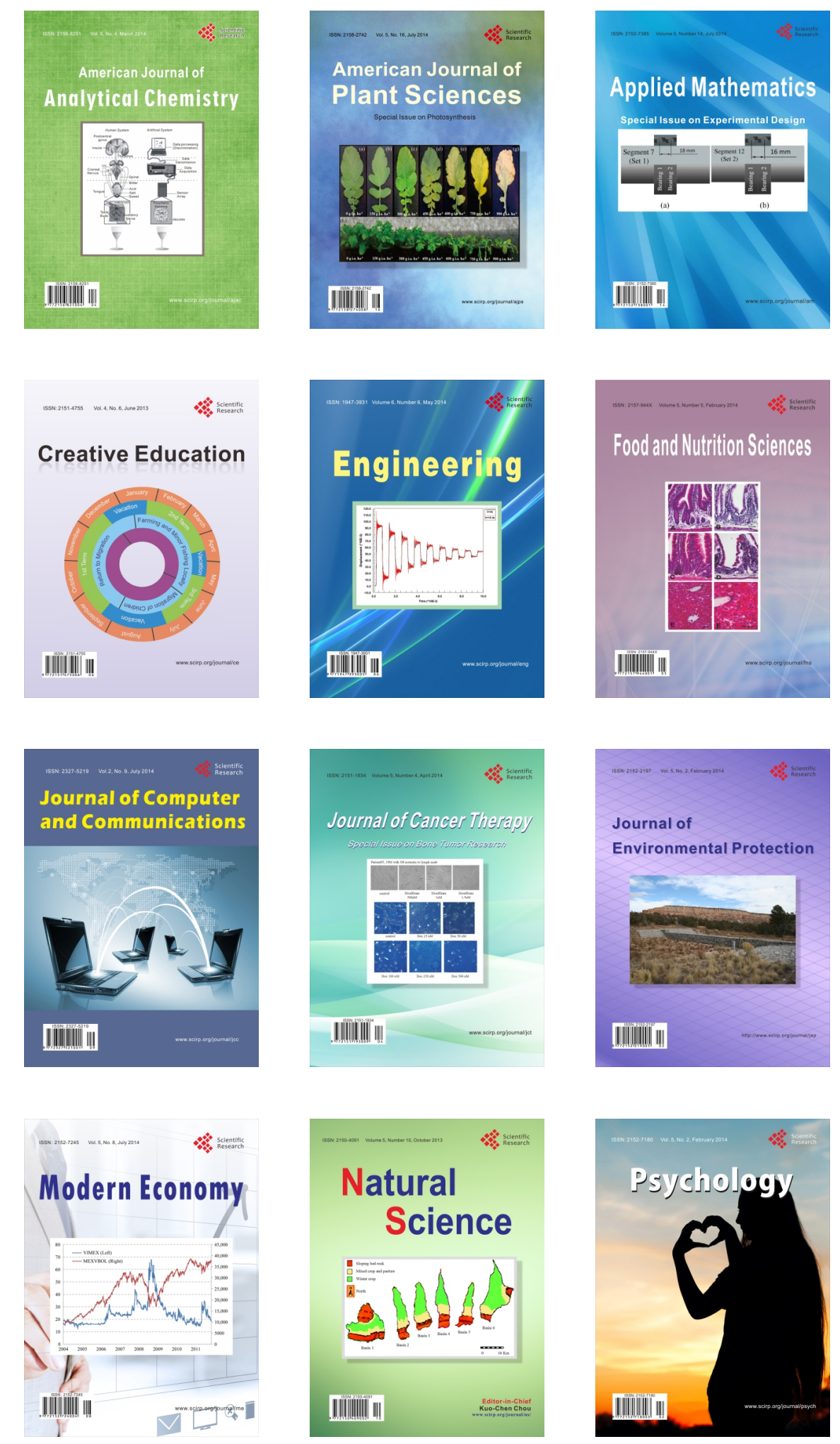